\title{
Necropolítica e Pesquisa-Intervenção sobre Homicídios de Adolescentes e Jovens em Fortaleza, CE
}

\author{
Luis Fernando de Souza Benicio ${ }^{1}$ \\ ${ }^{1}$ Universidade Federal do Ceará, CE, Brasil. \\ Jéssica Silva Rodrigues ${ }^{1}$ \\ ${ }^{1}$ Universidade Federal do Ceará, CE, Brasil. \\ Camila dos Santos Leonardo ${ }^{1}$ \\ ${ }^{1}$ Universidade Federal do Ceará, CE, Brasil.
}

\author{
João Paulo Pereira Barros ${ }^{1}$ \\ ${ }^{1}$ Universidade Federal do Ceará, CE, Brasil. \\ Dagualberto Barboza da Silva ${ }^{1}$ \\ ${ }^{1}$ Universidade Federal do Ceará, CE, Brasil. \\ Aldemar Ferreira da Costa ${ }^{1}$ \\ ${ }^{1}$ Universidade Federal do Ceará, CE, Brasil.
}

Resumo: Dado o crescimento da violência letal no Nordeste do Brasil, o artigo objetiva analisar psicossocialmente a problemática dos homicídios de adolescentes e jovens em Fortaleza, sob a perspectiva de adolescentes e jovens inseridos em territorialidades periferizadas da capital cearense, bem como de profissionais de políticas sociais que trabalham com tais segmentos. $\mathrm{O}$ texto é fruto de uma investigação alicerçada por diálogos da Psicologia Social com referências tanto pós-estruturalistas quanto pós/decoloniais e utiliza como principal operador conceitual a noção de necropolítica, de Achille Mbembe. Os dados foram produzidos por uma pesquisaintervenção realizada em quatro localidades de Fortaleza com as maiores taxas de homicídio em 2017, a partir de observações, entrevistas e grupos de discussão. Os resultados apontam que, de acordo com adolescentes/jovens e profissionais participantes do estudo, a elevação dos homicídios na adolescência/juventude em Fortaleza-Ceará decorre principalmente do agenciamento de três aspectos: transformações da dinâmica da violência urbana em função do fortalecimento de facções e de suas disputas territoriais, efeito da política do encarceramento em massa; investimentos equivocados em políticas de segurança pública orientadas pela "guerra às drogas" e centradas no policiamento ostensivo, na militarização das margens urbanas e na criminalização de segmentos juvenis pobres e negros (des)subjetivados como "matáveis"; precarização de políticas sociais destinadas a tais segmentos em tempos neoliberais. As conclusões do artigo apontam caminhos para prevenção e enfrentamento dos homicídios.

Palavras-chave: Homicídios; Adolescência; Juventude; Segurança Pública; Psicologia. 


\title{
Necropolitics and Intervention-Research on Homicides of Adolescents and Young People in Fortaleza, Ceará
}

\begin{abstract}
Given the growth of lethal violence in Northeastern Brazil, the article aims to psychosocially analyze the problem of homicides of adolescents and young people in Fortaleza, from the perspective of adolescents and young people inserted in peripheral territorialities of the capital of Ceará, as well as from the perspective of social policy professionals who work with such segments. The text is the result of an investigation based on dialogues of Social Psychology with both post-structuralist and post-decolonial references and uses Achille Mbembe's notion of necropolitics as the main conceptual operator. The data were produced by an interventionresearch conducted in the four locations in Fortaleza with the highest homicide rates in 2017, based on observations, interviews and discussion groups. The results indicate that, according to adolescents/young people and professionals participating in the study, the increase in homicides in adolescents/young people in Fortaleza, Ceará, stems mainly from the assumption of three aspects: transformations in the dynamics of urban violence as a result of the strengthening of criminal groups and of their territorial disputes, the effect of the policy of mass incarceration; misguided investments in "war on drugs" public safety policies, centered on ostensible policing, militarization of urban margins, and criminalization of poor and disenfranchised youth segments as "killable"; precarization of social policies aimed at such segments in neoliberal times. The article's conclusions point to ways of preventing and coping with homicides.
\end{abstract}

Keywords: Homicides; Adolescence; Youth; PublicSafety; Psychology.

\section{Necropolítica e Investigación-Intervención sobre Homicidios de Adolescentes y Jóvenes en Fortaleza, Ceará}

Resumen: Dado el crecimiento de la violencia letal en el Nordeste de Brasil, el artículo objetiva analizar psicosocialmente el problema de los homicidios de adolescentes y jóvenes en Fortaleza, desde la perspectiva de adolescentes y jóvenes insertos en territorialidades periferizadas de la capital de Ceará, así como de profesionales de las políticas sociales que trabajan con tales segmentos. El texto es el resultado de una investigación basada en diálogos de la psicología social con referencias post-estructuralistas y post/decoloniales y utiliza como principal operador conceptual la noción de necropolítica de Achille Mbembe. Los datos fueron producidos por una investigación-intervención realizada en cuatro localidades de Fortaleza con las mayores tasas de homicidio en 2017, a partir de observaciones, entrevistas y grupos de discusión. Los resultados apuntan que, de acuerdo con los adolescentes/jóvenes y profesionales participantes del estudio, el aumento de los homicidios en la adolescencia/juventud en Fortaleza, Ceará, se deriva principalmente de la orquestación de tres aspectos: transformaciones en la dinámica de la violencia urbana en función del fortalecimiento de facciones y de sus disputas territoriales, efecto de la política de encarcelamiento en masa; inversiones erróneas en políticas de seguridad pública orientadas por la "guerra a las drogas" y centradas en la vigilancia ostensible, en la militarización de márgenes urbanos y en la criminalización de segmentos juveniles pobres y negros (des)subjetivados como "matables"; precarización de las políticas sociales destinadas a esos segmentos en tiempos neoliberales. Las conclusiones del artículo apuntan a caminos para prevención y enfrentamiento de los homicidios.

Palabras clave: Homicidios; Adolescencia; Juventud; Seguridad Pública; Psicología. 


\section{Introdução}

O Atlas da Violência de 2018 indica que, no Brasil, 62.517 homicídios foram registrados em 2016 pelo Sistema de Informações sobre Mortalidade, do Ministério da Saúde (SIM/SM), o que implica uma taxa de 30,3 mortes por 100 mil habitantes (Cerqueira, et al., 2018). Entre 1980 e 2014, segundo Waiselfisz (2016), houve uma expansão progressiva, sistemática e ininterrupta desse tipo de violência no país.

Nesse quadro, os homicídios de adolescentes e jovens ganham destaque. Segundo o levantamento de Waiselfisz (2016), o aumento desse tipo de vitimização foi de 699,5\% entre 1980 e 2014. Já o $11^{\circ}$ Anuário Brasileiro de Segurança Pública sinaliza que 99,3\% das pessoas assassinadas em 2016 eram do sexo masculino; $81,8 \%$ tinham entre 12 e 29 anos e $76,2 \%$ eram negras (Fórum Brasileiro de Segurança Pública, 2017).

Na dinâmica da violência urbana brasileira das últimas décadas, destaca-se o processo de "Nordestinação" dos homicídios (Barros, Paiva, Rodrigues, Silva \& Leonardo, 2018), sendo isso mais evidente quanto ao assassinato de adolescentes. Conforme estudo sobre homicídios na adolescência no Brasil organizado por Borges e Cano (2017), dos nove estados com maior Índice de Homicídios na Adolescência (IHA), oito são do Nordeste. Sobressai-se, nesse panorama, o Ceará, estado brasileiro com maior IHA, e sua capital, Fortaleza, que apresenta o maior índice entre as capitais do país. Trata-se de um processo que se acentuou nas últimas décadas. Em 1989, por exemplo, o Ceará ocupava a vigésima colocação entre os estados brasileiros em termos de homicídios. Em 2005, ocupou a décima sétima posição. Em 2014, chegou à segunda colocação, sendo que em 2017 foi o que apresentou maior crescimento (52 homicídios por 100 mil). Ainda sobre o contexto cearense, 2017 registrou o maior número de crimes violentos letais e intencionais de sua história, totalizando 5.134, o que significou $48 \%$ de aumento em comparação com 2016. Deste total de assassinatos, 981 foram de adolescentes, isto é, cerca de 19 adolescentes foram mortos por semana, sendo em sua grande maioria do sexo masculino, mas devendo ser destacado o alarmante aumento de $196 \%$ da morte de adolescentes do sexo feminino em 2017 de acordo com o Comitê Cearense pela Prevenção de Homicídios na Adolescência (CCPHA, 2018).

Diante disso, o objetivo deste artigo é analisar psicossocialmente a problemática da intensificação dos homicídios juvenis na cidade de Fortaleza, sob a perspectiva de adolescentes e jovens inseridos em contextos periferizados da capital do Ceará, bem como de profissionais que trabalham com tais segmentos sociais em políticas públicas existentes nessas territorialidades. A problematização do fenômeno da violência letal contra determinados adolescentes e jovens ajuda-nos a tensionar continuidades e descontinuidades de formas de dominação e modos de subjetivação, mais especificamente práticas e racionalidades que amalgamam sistema prisional e segurança pública, por exemplo.

As reflexões deste artigo advêm da pesquisa guarda-chuva "Juventude e Violência Urbana: Cartografia de Processos de Subjetivação na Cidade de Fortaleza", financiada pela Chamada Universal $\mathrm{n}^{\circ}$ 01/2016 do Conselho Nacional de Desenvolvimento Científico e Tecnológico (CNPq), e desenvolvida pelo VIESES: Grupo de Pesquisas e Intervenções sobre Violência, Exclusão Social e Subjetivação, ligado ao Programa de Pós-Graduação em Psicologia da Universidade Federal do Ceará (UFC). Tal pesquisa tem o propósito de cartografar modos de subjetivação constituídos na articulação de práticas sociais em torno da questão da violência urbana envolvendo jovens em regiões da cidade de Fortaleza reconhecidas por elevados índices de homicídio.

Os referenciais teóricos da pesquisa são oriundos de estudos da Psicologia Social que se voltam às temáticas das violências e desigualdades sociais, dos processos de exclusão e dos modos de subjetivação, sobretudo no tocante aos segmentos adolescentes e juvenis no Brasil, dialogando com referenciais pós-estruturalistas, como Foucault, Deleuze, Guattari e Butler, e pós/decoloniais, a exemplo de Mbembe, Sayak Valencia, dentre outros. Compor nossas caixas de ferramentas em Psicologia Social a partir de interlocuções com essas referências não implica desatenção aos pontos em que elas diferem entre si no tocante a trajetórias, problemas, conceitos e objetos que acionam.

Para entendermos as condições de produção da violência letal que atinge precipuamente adolescentes e jovens negros e negras, tomaremos como operador conceitual a noção de necropolítica, apresentada pelo pensador camaronês Achille Mbembe (2016), experimentando conexões dela com outros conceitos e outras reflexões que nos parecem potentes ao nosso foco de problematização. Mbembe é considerado uma das principais referências pós-coloniais, por suas discussões não só sobre história e política africana, mas 
acerca do próprio mundo contemporâneo, a partir de deslocamentos de um eurocentrismo epistemológico. Suas problematizações e a de outras autoras e autores que seguem caminhos semelhantes vitalizam, assim, uma crítica social a partir da periferia do capitalismo (Hilário, 2016).

Mbembe (2016) caracteriza a necropolítica como uma tecnologia de produção e gestão da morte na contemporaneidade, partindo de uma releitura das noções de biopoder, biopolítica e racismo de estado, trazidas por Michel Foucault, de estado de exceção e estado de sítio, a partir de diálogos com Giorgio Agamben e Hannah Arendt, e de violência colonial, discutida por Franz Fanon. A necropolítica, portanto, constitui-se como um indicador tático para analisar a violência hoje, especialmente o fenômeno da destruição massiva de pessoas e a criação de mundos de morte que ilustram a continuidade da colonialidade e do imperialismo no âmbito da democracia liberal, na qual certos grupos populacionais são posicionados como "mortos-vivos", por meio de processos e práticas de desumanização, coisificação e indignificação de suas existências (Mbembe, 2017).

Esperamos que este artigo possa contribuir com novas incursões da Psicologia em estudos e inter(in) venções que enfoquem aspectos psicossociais das dinâmicas da violência letal contra adolescentes e jovens e das políticas públicas direcionadas à prevenção e ao enfrentamento dessa problemática.

\section{Método}

\section{Tipo de Pesquisa}

Os dados para a composição deste artigo foram oriundos de uma frente da pesquisa qualitativa da pesquisa guarda-chuva que se orienta pela perspectiva da pesquisa-intervenção. De acordo com Rocha e Aguiar (2003), a pesquisa-intervenção é um tipo de pesquisa participativa, teórico-metodologicamente ligada aos movimentos institucionalistas erigidos em meados do século XX e que visa investigar a diversidade qualitativa da vida cotidiana de sujeitos e grupos. A partir de situações-problema vivenciadas no contexto pesquisado e com vistas a transformações micropolíticas, esse tipo de pesquisa aposta em estratégias voltadas à análise coletiva de sentidos e práticas institucionais nesses cotidianos investigados. O caráter interventivo de nossa pesquisa envolveu a criação e potencializa- ção de dispositivos de análise coletiva em contextos periferizados de Fortaleza que apresentavam maiores taxas de homicídio na adolescência e juventude, com vistas a mapear, junto com profissionais e moradores ali inseridos, o plano das forças e os efeitos relacionados à problemática em questão, assim como estratégias singulares para lhe fazer frente.

Ao problematizar aspectos psicossociais ligados à produção e os efeitos da intensificação dos homicídios de adolescentes e jovens, tecemos a pesquisa-intervenção a partir de aproximações entre a política de pesquisa que Moraes (2010) chama da Pesquisa COM e o método da cartografia, trabalhado em produções como Passos, Kastrup e Escóssia (2009) e Passos, Kastrup e Tedesco (2014), a partir das discussões de Deleuze e Guattari sobre o rizoma. Isso significa direcionar a prática da pesquisa-intervenção em Psicologia ao acompanhamento de processos de produção de subjetividades por meio de um exercício de atenção à espreita, da inserção em um território existencial, pondo em análise o plano coletivo de forças que engendra o tema enfocado no estudo e exercitando novas políticas de narratividade na pesquisa. A partir dessa perspectiva de pesquisa, podemos acompanhar a própria processualidade da (re) construção do objeto da pesquisa e das variações das dinâmicas da violência urbana em Fortaleza a partir de 2015, suas implicações no cotidiano dos territórios investigados e nos modos de subjetivação de adolescentes e jovens ali operantes.

\section{Locais e participantes do estudo}

A pesquisa-intervenção tem se realizado nos quatro contextos territoriais da cidade com maiores taxas de homicídio de adolescentes e jovens no ano de 2017, segundo dados da Secretaria de Segurança Pública e Defesa Social (SSPDS), do Governo do Estado do Ceará, a saber: Grande Bom Jardim, Grande Jangurussu, Barra do Ceará e Mondubim (CCPHA, 2018). Todos esses contextos territoriais localizam-se na periferia da cidade, apresentam elevada densidade populacional, baixo Índice de Desenvolvimento Humano, contam com significativo número de assentamentos precários e são historicamente estigmatizados pela violência e pela desassistência dos poderes públicos locais. Não obstante, contam com entidades da sociedade civil atuantes e coletivos juvenis organizados, os quais têm pautado não só a letalidade crescente em seus bairros. 
Os resultados trazidos neste artigo foram produzidos em interlocução com os seguintes sujeitos, entre agosto de 2015 e julho de 2018: 1) adolescentes e jovens de 15 a 29 anos, de ambos os sexos, que tiveram amigos/as ou familiares, nessa mesma faixa etária, assassinados de 2015 em diante; 2) profissionais de políticas públicas que atuavam com adolescentes e jovens nesses contextos territoriais. Considerando os quatro contextos, participaram do estudo 97 adolescentes e jovens, em sua grande maioria do sexo masculino, residentes há pelo menos 1 ano nas regiões pesquisadas. Participaram, ainda, 54 profissionais de políticas sociais que atuam com adolescentes e jovens, com distribuição equânime em termos de gênero, sendo que todos e todas atuavam há pelo menos 1 ano em algum dos locais do estudo.

O conjunto de adolescentes e jovens que participaram da pesquisa era heterogêneo. Uma parte estava ou já esteve inscrita na dinâmica do tráfico de drogas, não frequentava a escola e não tinha acesso às poucas políticas sociais disponíveis em seus territórios. Já outros participavam de coletivos juvenis e/ou frequentavam equipamentos públicos existentes em seus locais de moradia, como escolas, projetos sociais e/ou equipamentos culturais públicos, sem histórico de cometimento de ato infracional. O grupo de profissionais que contribuiu com o estudo também foi diverso, pois tinham diferentes formações e filiações institucionais. Alguns também eram jovens e moravam nos territórios investigados.

A escolha dos sujeitos em cada lócus se deu por conveniência, seguindo a técnica da "bola de neve", em que cada participante indicava outro que pudesse colaborar com o estudo. Já o número de participantes foi definido por critério de "saturação teórica", a partir do qual a etapa de produção de informações se encerra quando se verifica que o campo não mais oferece, por hora, novos elementos para fundamentar a teorização. A fim de garantir o anonimato e proteção dos participantes do estudo, tendo em vista a complexidade da temática abordada e o acirramento dos conflitos territoriais na cidade, profissionais e adolescentes/jovens serão identificados apenas por números (por exemplo: Profissional 1 = P-1; Jovem $1=\mathrm{J}-1$ ). Também com a finalidade de garantir a segurança dos participantes, não serão dadas informações sobre especificamente em qual dos cenários de pesquisa eles estavam inseridos.

\section{Ferramentas metodológicas}

Utilizamos uma triangulação de ferramentas metodológicas: observações no cotidiano, entrevistas semiestruturadas e grupos de discussão, ambas com foco na tematização da violência urbana envolvendo jovens, tendo um dos destaques o fenômeno dos homicídios. As entrevistas se deram sob o manejo da cartografia (Tedesco, Sade, \& Caliman, 2013), privilegiando a polifonia de vozes em jogo, a experiência do dizer e seus processos de criação de si e do mundo. Todas as entrevistas foram audiogravadas.

Já os grupos de discussão se deram na forma de oficinas ou rodas de conversas e foram registrados por diário de campo, assim como as observações no cotidiano. Dada a diversidade de questões sobre conexões entre violência urbana e juventude que compõem o corpus da pesquisa, receberão destaque, neste artigo, somente aqueles trechos que diretamente abordam o tema dos homicídios de adolescentes e jovens, suas implicações no cotidiano de jovens e seus tensionamentos às políticas públicas, em especial o campo da segurança.

\section{Análise de dados e aspectos éticos}

Os materiais produzidos em campo foram analisados por meio da análise de discurso de inspiração foucaultiana, seguindo perspectiva adotada no estudo de Coimbra (2001), articuladamente à proposta da análise cartográfica (Barros,\& Barros, 2014). Em vez de estabelecer um direcionamento explicativo, o caminho da análise foi, a partir da construção de "analisadores", desemaranhar a rede de saber-poder-subjetivação que compõe a problemática dos homicídios de adolescentes e jovens, multiplicando sentidos e possibilidades de formulação de novas perguntas a esse respeito.

A pesquisa foi aprovada pelo Comitê de Ética em Pesquisa da UFC, estando de acordo com a Resolução nº 466 de 2012 do Conselho Nacional de Saúde.

\section{Resultados e discussão}

Os discursos dos participantes do estudo apontam três aspectos principais implicados no agravamento da problemática dos homicídios de adolescentes e jovens no Ceará e, particularmente, em Fortaleza: transformações da dinâmica da violência urbana a partir do fortalecimento de facções; direcionamentos militarizados das políticas públicas de segurança 
por parte dos governos estadual e municipal, bem como a naturalização de morte de corpos racializados; desamparos socioinstitucionais de adolescentes e jovens em territorialidades periferizadas como condição para o homicídio.

\section{Transformações da dinâmica da violência urbana no Ceará e o fortalecimento de facções}

O cenário de violência letal há tempos faz parte da realidade cearense (Barreira, 1999). Contudo, nossos interlocutores apontam que um dos aspectos a considerar quanto à intensificação dos homicídios nos últimos anos é a transformação da dinâmica da violência urbana no estado, se comparadas à década de 1990 e início dos anos 2000, épocas marcadas pela atuação de diversas gangues (Diógenes, 1999). Essas novas relações, práticas de vinganças, formas de dominação e normalização de condutas estão imbricadas ao fortalecimento de grupos que disputam mercados ilegais de drogas e armas, sobretudo nas periferias, chamados de "facções", com diversos "chefes" segmentados (Paiva, 2018). Um marco dessas transformações foi a repactuação local entre esses grupos criminosos, ocorrida entre o final de 2015 e meados de 2016, conhecida popularmente como "pacificação".

Segundo estudo feito por Barros et al. (2018), a "pacificação" se configurou especialmente pela proibição do ciclo de vinganças e práticas de homicídio entre grupos locais. Logo, esse "acontecimento-analisador" derivou da reorganização de grupos que disputam os mercados ilegais, com vistas ao seu próprio fortalecimento e lucro, e não de uma política de segurança pública e de promoção de justiça social por parte do Estado. As periferias da cidade experimentaram heterogeneamente esse marco das transformações da dinâmica da violência urbana. Ao mesmo tempo em que assistimos a pessoas festejando o "acordo", pela redução dos homicídios, a proibição de assaltos "nas áreas" e a possibilidade de transitar por espaços até então inviáveis, outras viam com ressalvas tais acontecimentos que consolidaram uma nova dinâmica criminal no estado.

Diminuiu as taxas [de homicídios], mas enquanto isso há um movimento do crime organizado se fortalecendo e os meninos que a gente atende sofrem mesmo nas mãos desses caras A galera se tornar escravo do tráfico e aí está sofrendo outros tipos de violência(P-6).

A quebra do "acordo" contribuiu para a elevação dos homicídios a patamares inéditos no estado em 2017 e nos primeiros meses de 2018. O contexto pós-pacificação configurou também novo mapa das disputas territoriais nas periferias pela expansão das façções, agravando restrições de trânsito entre os territórios, devido ao aumento do poder das facções sobre a vida e a morte nas periferias. No Ceará, atuam principalmente três grandes organizações "de fora" e uma que surgiu no próprio estado. Com efeito, essa foi uma das expressões mais ouvidas durante a pesquisa, a partir do final de 2016, "Tá tudo tomado" (J-3).

Tornaram-se mais recorrentes notícias de pessoas expulsas de suas casas e suas comunidades pelas facções, criando um contingente de "refugiados urbanos" e aumentando o número de pessoas em situação de rua. Diversos adolescentes e jovens nos relataram casos em que amigos de seu território, dominado por uma facção, foram assassinados por entrar em "território inimigo" (J-5), sob o domínio de uma facção rival, mesmo não tendo participação nos grupos em conflito.

Eliminar os inimigos é a prioridade de cada um desses grupos, mas aqui reside uma das principais mudanças da guerra entre facções em relação ao conflito anterior à maior participação desses grupos. A noção de "inimigo" nos discursos desses grupos é bastante elástica. "Simpatizantes" do outro grupo podem ser "decretados" (Paiva, 2018, p. 24).

Como expressão dessas novas dinâmicas da violência armada, os episódios de chacina têm sido mais recorrentes. De janeiro a julho de 2018, ocorreram pelo menos sete no estado, matando 47 pessoas (G1CE, 2018). A "Chacina de Cajazeiras", ocorrida em janeiro, a maior da história recente do Ceará, é paradigmática da ação das facções na gestão da vida e da morte em contextos periferizados. Esse episódio emblematiza como as chacinas se tornaram um modus operandi na destruição massiva de pessoas e de como essa instrumentalização destrutiva de corpos se tornou regra do espaço público local (Mbembe, 2017).

Entendendo as chacinas como dispositivos necropolíticos em ascensão no estado e a relação de 
grande parte delas com o que é designada localmente como "guerra de facções", em que se baseia esse modo de fazer morrer (não necessariamente exercido pelo Estado) e o que ele diz sobre os contextos territoriais afetados pela maior parte das chacinas?

Para Mbembe (2017), a base normativa do direito de matar, além do racismo e da colonialidade, são o estado de exceção e o que ele chama de relação de inimizade. Cavalcante (2011), apropriando-se das ideias de Agamben (2004), chamou de "territórios de exceção" os espaços da periferia de Fortaleza em que sobretudo adolescentes e jovens são mortos cotidianamente sem que haja responsabilização por esses assassinatos.

Mbembe (2017) retorna a Fanon para elucidar como funciona esse poder de morte:

A cidade do colonizado é um lugar de má fama, povoado por homens de má reputação. Lá eles nascem, pouco importa aonde e como; morrem lá, não importa aonde ou como. [...] A cidade do colonizado é uma cidade com fome, fome de pão, de carne, de sapatos, de carvão, de luz. A cidade do colonizado é uma vila agachada, uma cidade ajoelhada (Fanon, 2010, p. 41).

As periferias urbanas cearenses onde as chacinas se fazem mais frequentes se assemelham à descrição mbembeana das colônias e aos apontamentos fanonianos sobre a cidade do colonizado. Isso porque são palcos de um regime de terror particular, marcado pelo exercício de um poder à margem da lei, no qual os processos de racialização têm um papel crucial para o estabelecimento de uma guerra aparentemente infindável.

O direito soberano de matar não está sujeito a qualquer regra na colônia. Lá, o soberano pode matar a qualquer momento ou de qualquer maneira. A guerra colonial não está sujeita a normas legais e institucionais. A paz não constitui necessariamente a consequência natural de uma guerra colonial. De fato, a distinção entre guerra e paz não é pertinente (Mbembe, 2017, p. 36).

As atuais dinâmicas da violência urbana têm como um de seus efeitos a produção de "subjetividades acuadas" (Barros et al., 2018, p. 122), agenciadas por medos difusos, aprisionadas a céu aberto pelas divisões simbólico-espaciais dos territórios "faccionados". Em nossa cartografia, um exemplo disso se deu na "V Caminhada pela Paz do Grande Bom Jardim”, em maio de 2018, organizada por entidades da sociedade civil que atuam na região. Muitos discentes de escolas da região não puderam comparecer ao ato, pelo receio de transitar no bairro, pois o itinerário da caminhada passaria por "ruas de uma facção diferente da que domina a região onde fica a escola" (J-10).

Destacamos um trecho da entrevista com um dos profissionais participantes do estudo, que também morava no bairro onde trabalhava. Sua narrativa indica que essa presença intensa da morte acarreta uma relação com seu bairro marcada por estigmatizações e sentimento de vergonha (Barros et al., 2018):

Quase todos os dias, você se deparava em algum lugar, no percurso, com algum corpo estirado. Esses lugares de fronteira são espaços de violência, disputas, corpos estendidos pelo chão. $\mathrm{E}$, nessa dinâmica da violência, e volta aquela coisa de ter vergonha do estigma de dizer que é daqui (P-2).

Um dos efeitos dessas transformações psicossociais da violência urbana é que adolescentes e jovens das periferias, em especial negros e pobres, em sua maioria do sexo masculino, mas com destaque para o aumento do número de mortes de adolescentes do sexo feminino e mulheres adultas nos conflitos territoriais (CCPHA, 2018), encontram-se em um "fogo cruzado" dessa maquinaria de produção massiva da morte de existências descartáveis.

Outro ponto a realçar é que a faccionalização da dinâmica criminal brasileira é imanente à política de encarceramento em massa adotada no país (Borges, 2018; Wacquant, 2011). Tal política põe a prisão no epicentro das "crises" da segurança pública, pois confere à dinâmica dos presídios centralidade na própria dinâmica criminal nas periferias urbanas e, consequentemente, na intensificação de homicídios nas margens urbanas (Manso,\& Dias, 2017). A faccionalização do próprio sistema prisional brasileiro oferece condições à proliferação e fortificação de grupos locais como os que atuam no contexto cearense. No Ceará, por exemplo, após a quebra do "acordo" entre as facções, houve um reordenamento dos presídios para que cada unidade correspondesse a cada um dos grupos. 
Eis a perversa teia necropolítica que entrelaça sistema prisional e segurança pública no Brasil, tendo o Ceará como um caleidoscópio de tal cenário: a aposta em uma "guerra às drogas racialmente enviesada” (Alexander, 2017, p. 20), na militarização da vida nas favelas, na repressão, punição e controle penal é parte constitutiva do problema que anuncia, retoricamente, querer aplacar. Dado o caráter sistêmico com que essa situação do encarceramento em massa se apresenta, mais do que uma "crise", trata-se, pois, de um "projeto" racista de produção e gestão da morte de existências abjetas (Borges, 2018).

\section{Políticas de segurança pública e a naturalização da morte de "envolvidos"}

O Ceará tem sido palco do recrudescimento de um modelo segurança pública operado por ações predominantemente ostensivas e de militarização das periferias encampadas tanto pelo governo do estado quanto pela prefeitura de Fortaleza. No caso das ações do governo estadual, a principal ilustração disso é a expansão do "Raio". Já as apostas da prefeitura de Fortaleza têm sido armar a guarda municipal e instalar "células de proteção comunitária" em bairros da periferia, que consistem em torres de vigilância que lembram o dispositivo panóptico, equipadas com câmeras de vigilância 24 horas e patrulhamento integrado com participação de guardas municipais e policiais militares (Prefeitura de Fortaleza, 2018).

Profissionais e moradores dos territórios pesquisados assinalam que as atuais políticas de segurança pública do estado do Ceará também são peça-chave do panorama dos homicídios de adolescentes e jovens. Foram muitos os que creditavam a intensificação dessas mortes a uma política de eliminação de grupos populacionais e segmentos sociais específicos, a partir da intersecção de marcadores de classe, raça, gênero e idade.

Está se matando mais jovens do que qualquer outra parte da população e eu vejo que essas mortes não acontecem de forma aleatória. Existe aí um recorte de classe, cor e raça, território onde mora e idade. Por quê o Estado está tendo essa política de extermínio da juventude? A política que o governo está tendo com relação à segurança é produzir mais violência. Por que? É colocar polícia na rua armada, entendeu? Qual a política de segurança que se utiliza aqui na nossa cidade? É uma política de monitoramento das favelas (P-14).

Um dos casos mais emblemáticos da participação de agentes de segurança pública do estado na violência letal foi a "Chacina do Curió", em novembro de 2015, na qual 11 moradores, dentre eles sete adolescentes, de bairros da região da Grande Messejana foram executados em uma única madrugada (Barros, Benicio, Silva, Leonardo \& Torres, 2017a). Quarenta e quatro policiais militares foram indiciados, mas, até o primeiro semestre de 2018, ainda não foram julgados.

Especificamente no Ceará, entre 2013 e 2017, segundo dados da própria Secretaria de Segurança Pública e Defesa Social do Estado do Ceará (SSPDS), as mortes por intervenção policial triplicaram (Melo, 2018). Por seu turno, também cresceu o número de mortes de policiais, que apresentou elevação de $54 \%$ no intervalo entre o primeiro semestre de 2013 e o igual período de 2017 (CCPHA, 2017). Ou seja, nem policiais nem adolescentes/jovens das "quebradas" saem vencedores nesse cenário de recrudescimento dos dispositivos de segurança militarizados que contribuem para aprofundar a guetificação das margens urbanas locais, pela combinação de estigmas, restrições, confinamentos espaciais e aprisionamentos institucionais (Wacquant, 2008).

As abordagens policiais violentas também foram ponto recorrente nos discursos de adolescentes e jovens participantes da pesquisa, evidenciando que a governamentalização bio/necropolítica pelos dispositivos de segurança opera por meio da criminalização. Muitos interlocutores ressaltam a seletividade racial dessa violência institucional. Em um dos nossos grupos de discussão, um jovem negro era chamado pelos colegas de "para-raio", por ser constantemente abordado por policiais do Raio. Segundo os participantes do grupo, isso acontecia por aquele jovem ter "cara de bandido" (J-20) e porque "o lugar onde a pessoa mora, o modo de vestir, a cor da pele definem quem a polícia para" (J-21).

As juventudes "Para-Raio", enquadradas como "elementos suspeitos" (Ramos,\& Musumeci, 2005), assemelham-se aos 'maus objetos' mencionados por Mbembe (2017). Não têm direito ao seu corpo, o que se expressa pelas violências cotidianas como os "baculejos", tampouco aos seus lares, o que se exemplifica por invasões de residências sem ordem judicial. A rigor, "não têm qualquer direito a ter direitos. São 
regidos pela lei da desigualdade. Esta desigualdade e a lei que a institui e na qual se baseia fundam-se no preconceito da raça" (Mbembe, 2017, p. 34).

Em outro grupo de discussão que propusemos, um dos jovens nos disse: "Eu me sinto mais seguro pelo crime do que pela polícia” (J-2). Isso nos dá pistas de que a aposta no policiamento ostensivo e no vigilantismo tem provocado mais tensionamentos e desconfianças de segmentos juvenis em relação às forças de segurança, além de não ser capaz de aplacar a escalada de violência armada, a julgar pelas crescentes taxas de crimes violentos letais e intencionais. Para Barreira (1999), as humilhações e discriminações sofridas por essas juventudes ajudam a entender suas desconfianças em relação às forças de segurança:

Por não confiar na polícia e na justiça, vai se construindo no imaginário popular que a violência, ela muitas vezes resolve, né? Tipo, o cara foi ali, roubou, "ah, então vamo meter a peia que vai dar jeito”. Tá aí a nossa sociedade sempre foi muito conservadora, né? Acaba que essa questão de resolver alguns conflitos pela violência acaba se tornando a própria justiça mermo, sabe? (P-2).

A "guerra às drogas" é imanente a essas práticas de segurança pública e se constitui como um dos principais dispositivos bio-necropolíticos no cotidiano das periferias. Tal aspecto é reconhecido na seguinte fala:

Se você tem um Estado que não trata sobre a questão de drogas de uma forma séria, como uma questão de saúde, não como uma questão de polícia, você tem um Estado que tá batendo o martelo ali pra criminalizar pessoas da periferia, sobretudo a juventude (P-2).

Na condição de dispositivo bio-necropolítico, atua no gerenciamento da vida (Benevides,\& Preste, 2014; Ribeiro Junior, 2016), e também na produção e gestão das mortes (Borges, 2018). Sua operacionalização traduz bem a característica da ocupação colonial na atualidade segundo Mbembe (2017), pois articula disciplina, biopolítica e necropolítica na criminalização de juventudes subalternizadas. As políticas de segurança orientadas pela guerra às drogas também instalam estado de exceção permanente e indistinções entre guerra e paz nas colônias contem- porâneas, articulando política de morte e política de racialização.

[...] A diferença do tráfico da parte nobre da cidade para a favela é que aqui posso fazer qualquer coisa, aqui tá circunscrito que eles não têm direitos, portanto eu posso chegar e fazer o que eu quiser; "eu posso matar". Já na parte nobre não (P-1).

Para Mbembe (2017, p. 17), a necropolítica remete-se continuamente "a uma noção ficcional do inimigo". Segundo aponta Cruz, Minchoni, Matsumoto e Andrade (2017), em diálogo da Psicologia com a criminologia crítica, a construção do inimigo delinquente se tornou política pública no Brasil, em nome da "defesa social". As autoras frisam ainda que: "O medo construído a partir de um inimigo suposto (e que, justamente por ser suposto, é inesgotável) e invariavelmente identificado nos setores populares, cumpriu o seu dever: a força policial, hoje, está autorizada a atuar no patamar do massacre" (Cruz et al., 2017, p.246).

Um dos principais operadores psicossociais da necropolítica em territorialidades cearenses tem sido a implícita divisão da população entre "cidadão" e "não cidadão". O "não cidadão" é geralmente identificado como "vagabundo", "bandido", "de menor", "traficante", "alma sebosa", "pirangueiro" e pelo termo "envolvido", aglutinador dos anteriores. Nas atuais dinâmicas da violência urbana no Ceará, quem é enquadrado como "envolvido" são adolescentes e jovens negros e inseridos nas periferias urbanas, a partir da instrumentalização racista do medo (Mbembe, 2016). São esses adolescentes e jovens que são reconhecidos como algozes da violência e alvos das forças militarizadas de segurança. O extermínio desses corpos, figuras atuais do homo sacer (Agamben, 2009) não causa comoção social e é passível de adesão social e mórbida espetacularização.

A figura do "envolvido" como "sujeito matável" guarda semelhança com a condição do que Mbembe (2017) chama de "escravo contemporâneo". Este, por ser destituído de estatuto político, é submetido ao que o camaronês denomina de "estado de injúria", pelo predomínio de uma "morte social". Em de suas declarações públicas, o então secretário de segurança do estado sentenciou que, em sua gestão, o "bandido" teria dois caminhos: "justiça ou cemitério" (Victor, 
2017). Perpassando esse tipo de posicionamento, é possível observar uma possível face necropolítica da segurança pública, que articula uma espécie de direito penal subterrâneo (Zaffaroni, 2007), privando os ditos "bandidos" de sua condição de pessoa.

O binarismo entre "cidadão" e "não cidadão/ envolvido" perpassou posicionamentos públicos de autoridades do campo da segurança no estado acerca das chacinas de maior repercussão social e midiática, como as Chacinas do Curió e de Cajazeiras. Após noticiadas essas chacinas, as primeiras manifestações públicas das autoridades de segurança prometiam averiguar a existência de antecedentes criminais das vítimas e seu envolvimento ou não com facções criminosas (Barros et al., 2017a).

Em outubro de 2017, a Secretaria da Segurança Pública e Defesa Social (SSPDS) declarou que 47\% das pessoas assassinadas eram ligadas a facções ${ }^{1} \mathrm{e}$ $88 \%$ tinham envolvimento direto com drogas ${ }^{2}$. Tais narrativas acabam por potencializar a insensibilidade social frente a essas mortes. Ao falar das mudanças na política de segurança pública no Ceará nos últimos 20 anos, Paiva (2018) aponta um elemento que permanece historicamente: em meio às formações dos primeiros mercados ilegais de drogas nas periferias, na década de 90, ao aumento sistemático dos homicídios nos anos 2000, em função da expansão desses mercados, ao investimento crescente em políticas de lei e ordem fundamentadas na promoção de policiamento ostensivo, como o Programa "Ronda do Quarteirão" e a expansão do "Raio", e à consolidação de dinâmicas criminais no Ceará pelas chamadas "facções", a partir de repactuações entre tais grupos entre 2015-2016, as mortes de jovens nas periferias são minimizadas como "acerto de contas entre bandidos".

Milhares de jovens morreram nos últimos 20 anos sem que suas vidas fossem objeto de cuidado do Estado, das agências de segurança e justiça. Durante anos, moradores dessas localidades assistiram a morte sistemática dos membros desses grupos e as forças policiais explicaram os crimes como acertos de contas sem, também, interferir na mortalidade dessas pessoas (Paiva, 2018, p. 25).

Ao discutir sobre o biopoder, Foucault (2005, p. 214) já nos advertia que o racismo é "a condição de aceitabilidade de tirar a vida numa sociedade da normalização", seccionando e hierarquizando o corpo população, estabelecendo os que devem viver e os que devem morrer. Realizando uma espécie de "enegrecimento" de tal discussão, radicalizando-a pelo realce da matriz colonial desse poder hierarquizante, utilizando, para tanto, o exemplo da escravidão, o pressuposto da noção mbembeana de necropolítica é de que a expressão máxima da soberania é essa capacidade de ditar quem pode viver e quem deve morrer.

Nesse ponto da discussão entre que vidas são ou não reconhecidas como dignas de vida, é possível estabelecer diálogos entre a necropolítica e as discussões de Butler (2015) sobre guerras contemporâneas. A compreensão dessa produção e gestão cotidiana da morte, que, para se estabelecer, desumaniza certas existências para as desabilitar socialmente, requer a análise do estatuto político de determinadas vidas e o sentido de sua eliminação. Afinal, nem todas são consideradas vidas de fato, razão pela qual suas mortes não geram comoção social e não são passíveis de luto. Por meio desses diálogos teóricos, o extermínio de certas existências, ao invés de um efeito colateral de certas políticas de segurança, é um dos pontos de sustentação do regime político atual. Com efeito, a superação desse estado de coisas requer a problematização de operações de poder implicadas no enquadramento e nas molduras que apreendem ou não certas vidas como perdidas ou lesadas (Butler, 2015).

A necropolítica pode ser, portanto, um paradigma explicativo dos processos de naturalização dos homicídios de determinados segmentos populacionais inseridos em territorialidades periféricas. Ainda que seja necessário considerar aspectos novos nessa produção de mortes, o extermínio de certos grupos populacionais também é uma das mais evidentes manifestações da perpetuação do racismo e de um projeto genocida atrelado à história colonial do país.

Desmontando o mito de democracia racial, Nascimento (2017, p. 19) aponta que "da escravidão, no início do período colonial, até os dias que correm, as populações negras e mulatas têm sofrido um genocídio institucionalizado, sistemático, embora silencioso". O Atlas da Violência de 2018 ilustra a desigualdade racial no Brasil, atestando a concentração de homicídios na população negra: no período entre 2006 e 2016, a taxa de homicídios de negros cresceu $23,1 \%$ e a de não negros teve uma redução de $6,8 \%$ (Cerqueira et al., 2018).

Além das disputas entre facções e do recrudescimento da militarização das periferias decla- 
rando "guerra ao crime organizado", o crescimento dos homicídios deve-se à reiteração de processos de banalização da violência em sua condição de dispositivo socialmente aceitável como forma de resolução de conflitos e publicamente requerido como política de segurança. Ou seja, a produção da morte é também tributária do engendramento de modos de subjetivação atravessados por desejos de aniquilação.

Os participantes também chamaram atenção para estigmatização de periferias e criminalização de sujeitos subalternos pelas narrativas de dispositivos midiático-empresariais, destacadamente programas policialescos: "A mídia também contribui com isso. Aí você vê 18 horas de canal policial, manhã, tarde noite e madrugada, né?" (P-3). O trecho a seguir, extraído de uma entrevista feita com um dos jovens que participaram da pesquisa, permite refletirmos sobre a atuação de tais dispositivos na potencialização de uma "adesão subjetiva à barbárie", a partir do uso do medo como ferramenta de governamentalização (Barros et al., 2017a; Coimbra, 2001; Coimbra,\& Nascimento, 2003).

Eu apanhei na cara quando tava fumando na praça. Eu via as abordagens, sempre foi algo muito truculento, mas [...] é como se essa questão dessa maquiagem, dessa coisa da mídia alienando e não deixando a gente perceber, o próprio sistema, que não te deixa tempo pra pensar. Então, assim, por causa de tudo isso parece que não importa aquilo que acontece na periferia, sabe?

\section{Desamparos institucionais como parte da política de morte}

Além da produção direta da morte, a necropolítica opera também na desabilitação e inviabilização de vidas (Mbembe, 2016). Isto é, além do homicídio, a tecnologia de produção e gestão da morte opera pelo abandono e desamparo e, ao mesmo tempo, pela naturalização da condição ilegítima e abjeta de certas existências. Ao serem interpelados sobre o que tem gerado a intensificação de homicídios juvenis, que seguem vitimando principalmente negros, pobres e moradores de periferias (CCPHA, 2018), a maior parte dos participantes do estudo mencionou a ausência, precarização ou insuficiência de políticas públicas para adolescentes e jovens.
Um dos aspectos ressaltados pelos profissionais foram as fragilidades na rede de proteção desse segmento, relatando lacunas de projetos, programas e políticas permanentes, dificultando a redução da violência nesses territórios. Segundo falas como a do profissional abaixo, a ausência ou falta de consistência de ações voltadas à proteção social e garantia de direitos de juventudes favorece suas inserções nas dinâmicas da violência urbana: "o moleque nasce e cresce negligenciado pelo Estado. Por isso que tem a história, né, o pessoal fala que quem provoca a morte daquele jovem é o Estado. Então o Estado, ele se ausenta, ele, olha, deixa que morra, né" (P-1). São justamente nessas áreas marcadas pelo abandono que as facções encontram condições propícias para se estabelecer e cooptar adolescentes e jovens perversamente (in)visibilizados (Sales, 2007).

Corroborando posicionamentos como esse, diversos adolescentes e jovens também apontam que a fragilização das políticas públicas é um dos fatores que contribuem para o crescimento da violência letal contra o segmento juvenil: "É o que a maioria dos meninos diz, que o crime tá expandido, véi. Onde não há cultura, o crime vira espetáculo e por isso que tá o espetáculo das facções, entendeu, em todas as quebradas" (J-1).

Dados do Comitê Cearense pela Prevenção de Homicídios na Adolescência (CCPHA), apontam um conjunto de evidências de que a problemática dos homicídios juvenis está relacionada à desigualdade social e desamparo institucional. Para conectar com nossa discussão, destacam-se: a) a pouca participação dos jovens em projetos sociais, mais de $50 \%$ dos jovens assassinados não tinham acesso a atividades desse tipo; b) a falta de atendimento a rede de amigos e familiares dos adolescentes assassinados, em que (64\%) tiveram amigos assassinados; c) a precária inserção no mercado de trabalho, somente $2 \%$ tiveram um tipo de experiência de aprendiz, no mercado formal de emprego. Ainda de acordo com o CCPHA, mais de $70 \%$ dos jovens assassinados em 2015 não frequentavam a escola e $72,6 \%$ tinham acesso precário à saúde, procurando a Unidade Básica de Saúde apenas quando estavam doentes e, na maioria dos municípios, mais da metade dos entrevistados nunca frequentaram nenhum projeto social. Além disso, a maior parte dos jovens assassinados tiveram inserção precária no mercado de trabalho. Esses dados refletem o cenário de desigualdades e desassistências no 
qual se encontram os jovens cearenses, maximizando a condição precária de suas vidas (Butler, 2015) e suas vulnerabilizações às dinâmicas de violência.

A dificuldade de acesso a políticas públicas, seja pela falta de serviços de saúde, educação, cultura e lazer, seja pela impossibilidade de acesso a esses serviços, mesmo que precarizados, é um dos fatores precípuos para a intensificação dos homicídios nas periferias de Fortaleza. Acerca das condições de produção das mortes de adolescentes e jovens nesses territórios, destaca-se a influência da criminalização desse segmento expressa pela negação de oportunidades ao longo de todas as etapas da vida. Para nos ajudar na exemplificação disso, trazemos o depoimento dado por um jovem em um dos grupos de discussão sobre sua própria trajetória:

Eu sou um sobrevivente né? Não entrei nessa estatística, como quiseram que eu entrasse. Pra mim buscar oportunidade de emprego, eu tive que sair da minha comunidade, porque não tem, entendeu? Tipo, se eu for pra outros cantos agora não vai me dar emprego, porque eu sou favelado, entendeu? O sistema faz com que isso assim aconteça. Só que não tem nada, nada pra mudar (J-1).

O desamparo institucional característico do cotidiano dessas juventudes está relacionado ao subinvestimento nas políticas sociais, ao passo que há um aumento dos gastos com policiamento ostensivo e tecnologias de vigilância das periferias estigmatizadas como perigosas. Como analisador desse panorama típico de tempos neoliberais, no contexto de Fortaleza, desde 2012, há redução do gasto real com políticas para infância e adolescência no Município, segundo relatório do Fórum DCA-CE (Braz, Silva,\& Maciel, 2017).

Em relação às políticas de juventudes, os Cucas têm sido equipamentos importantes no contexto local, ofertando atividades de cultura, arte, lazer, esporte e profissionalização a jovens em bairros da periferia da capital cearense com altos índices de homicídio. Entretanto, jovens e profissionais entrevistados ressaltam a insuficiência dos equipamentos existentes, que abrangem apenas três das sete regionais da cidade.

Além disso, em nossas inserções em atividades cotidianas nos equipamentos em questão, percebe- mos as dificuldades que os profissionais encontram para alcançar as juventudes mais vulnerabilizadas e expostas aos homicídios. Em um dos equipamentos, essas dificuldades foram acentuadas por demissões de educadores sociais com maior vinculação territorial e que experimentavam práticas instituintes de aproximação de juventudes estigmatizadas da região. Para ilustrar esse movimento simultâneo de precarização de políticas sociais e aumento de gastos com segurança, jovens da região do Grande Jangurussu ouvidos na pesquisa seguidas vezes denunciaram que, no mesmo equipamento cultural em cuja calçada foi construída a primeira "célula de proteção comunitária", imponente e onerosa, as obras do teatro daquele Cuca, iniciadas há anos, nunca foram finalizadas.

Dados da Célula de Vigilância Epidemiológica do município de Fortaleza sobre a distribuição espacial dos homicídios de crianças e adolescentes demonstram que um terço dessas mortes ocorreu numa área que corresponde a $4 \%$ da cidade, onde vivem $13 \%$ da população. Apontam, ainda, que os homicídios estão mais intensamente concentrados em assentamentos precários, onde também prevalecem doenças de determinação social e se direcionam mais vigorosamente práticas repressivas no campo da segurança discutidas alhures. Esse cenário trata-se de uma das materializações da gestão penal da miséria e da insegurança (Cruz et al., 2017), característica do que Wacquant (2001) denomina de "Estado Centauro", dotado de cabeça neoliberal e corpo autoritário para gerir, pela reiteração da força colonialista, as consequências das desigualdades sociais.

\section{Considerações finais}

No contexto da "nordestinação" da violência letal observada no Brasil nas últimas décadas, procuramos, a partir de uma pesquisa-intervenção, analisar psicossocialmente a problemática da intensificação de homicídios de adolescentes e jovens no Ceará, particularmente em sua capital, considerando-a uma das principais expressões da necropolítica à brasileira. A dimensão interventiva da pesquisa foi materializada pela criação de dispositivos de análise coletiva voltados à problematização e desatualização da questão junto a adolescentes/jovens e profissionais inseridos em contextos territoriais com as mais elevadas taxas de homicídios da capital brasileira onde mais morrem adolescentes e jovens. 
Segundo adolescentes, jovens e profissionais de políticas sociais que participaram da pesquisa-intervenção, o agravamento do panorama dos homicídios se dá a partir da conexão de aspectos como o fortalecimento de facções e o acirramento de suas disputas territoriais, sendo consequência de uma política de encarceramento em massa, investimentos equivocados em policiamento ostensivo e dispositivos de vigilância que criminalizam adolescentes e jovens subalternizados. Vale ressaltar que esses aspectos se atualizam em um contexto de recrudescimento da militarização dos cotidianos periféricos orientados pela lógica do confronto, em detrimento do fomento à inteligência e integração das forças de segurança numa perspectiva democrática, além do agravamento de históricas situações de desigualdade social e desamparo institucional, que atingem especialmente adolescentes e jovens mais pobres e negros, bem como seus familiares (Barros, et al., 2017), maximizando a condição precária de suas vidas.

Não obstante, a fim de assinalar horizontes possíveis frente à problemática levantada, destacamos algumas recomendações elaboradas pelo CCPHA como pistas importantes para prevenção da questão dos homicídios que vitimam adolescentes e jovens do estado: a) apoio e proteção às famílias vítimas de violência; b) ampliação de programas e projetos voltados para adolescentes e jovens vulneráveis aos homicídios c) qualificação urbana dos territórios vulneráveis aos homicídios; d) mediação de conflitos e proteção a ameaçados; e) oportunização de trabalho e renda; f) formação de policiais na abordagem ao adolescente; g) controle de armas de fogo e munições e h) mídia sem violações de direitos (CCPHA, 2017). Tais recomendações se coadunam com algumas saídas assinaladas também por quem participou de nossa pesquisa-intervenção. Nessas participações, por exemplo, profissionais realçaram a importância de apostar na construção de políticas públicas feitas com jovens, e não só para jovens.
Complementarmente, segundo alguns especialistas na área da segurança pública, é necessário que o país consiga priorizar uma agenda de ações efetivas na contramão do populismo punitivo-penal (Carielo,\& Grillo, 2017). Essa agenda pode se efetivar com: a) a construção de mecanismos eficientes de redução da violência policial, o que envolve problematizar a militarização da polícia e da política de segurança; b) a implementação da prevenção e da investigação dos crimes contra a vida como medidas prioritárias; c) o controle das armas de fogo de forma duradoura; d) o desenvolvimento amplo de programas de prevenção social da violência voltados para os mais vulneráveis à violência; e) a redução drástica do encarceramento; f) a adoção de políticas de drogas que protejam os que são atingidos pela violência sistêmica de alguns mercados de drogas, o que passa pelo fim da "guerra às drogas" (Carielo,\& Grillo, 2017).

Além das estratégias de prevenção e enfrentamento que foram elencadas, ao habitar diversos territórios existenciais em nossa pesquisa-intervenção, experimentamos práticas assentadas em micropolíticas voltadas à problematização do desejo no campo social agenciada por políticas de indiferença e à disputa de narrativas frente ao estatuto político de certas vidas cujos homicídios são naturalizados pela maquinaria de produção de subjetividades punitivo-penais, insensíveis ou aderentes à morte das populações periféricas. Ainda dentro dessa dimensão micropolítica, destacamos a importância de um aspecto que ganhará centralidade em outras incursões investigativas e outros artigos: a construção de espaços de participação social junto às territorialidades subalternizadas e o reconhecimento de práticas de resistência juvenis às violências em curso nas margens urbanas, que apostam na invenção de outros modos de habitar a cidade, na contramão de práticas higienistas e segregacionistas que minam a produção do plano do comum.

\section{Referências}

Agamben, G. (2004). Estado de exceção. São Paulo, SP: Boitempo.

Agamben, G. (2009). Homo Sacer: O poder soberano e a vida nua (2a ed.). Belo Horizonte, MG: Editora UFMG.

Alexander, M. A. (2017). A nova segregação: Racismo e encarceramento em massa. São Paulo, SP: Boitempo.

Barreira, C. (Coord.) (1999). Ligado na galera: Juventude, violência e cidadania na cidade de Fortaleza. Brasília, DF: Unesco. 
Barros, J. P. P., Benício, L. F. S., Silva, D. B., Leonardo, C. S., \& Torres, F. J. P. (2017a). Homicídios juvenis e os desafios à democracia brasileira: Implicações ético-políticas da psicologia. Psicologia: Ciência e Profissão, 37(4), 1051-1065. https://doi.org/10.1590/1982-3703002892017

Barros, J. P. P., Paiva, L. F. S., Rodrigues, J. S., Silva, D. B., \& Leonardo, C. S. (2018). "Pacificação” nas periferias: Discursos sobre as violências e o cotidiano de juventudes em Fortaleza. Revista de Psicologia, 9(1), 117-128.

Barros, L. M. R., \& Barros, M. E. B. (2014). Pista da análise: O problema da análise em pesquisa cartográfica. In: E. Passos, V. Kastrup, \& S. Tedesco (Orgs.), Pistas do método da cartografia: A experiência da pesquisa e o plano comum (Vol. 2, pp. 373-390). Porto Alegre, RS: Sulina.

Benevides, P. S., \& Prestes, T. K. A. (2014). Biopolítica e governamentalidade: Uma análise da Política Nacional sobre Drogas. Estudos Contemporâneos e Subjetividade, 4(2), 274-287.

Borges, D., \& Cano, I. (2017). Índice de homicídios na adolescência: IHA 2014. Rio de Janeiro, RJ: Observatório de Favelas.

Borges, J. (2018). O que é encarceramento em massa? Belo Horizonte, MG: Letramento.

Braz, M. A., Silva R. M., \& Maciel, T. A. (2017). Prioridade absoluta e os indicadores fiscais do município de Fortaleza: análise do quadriênio 2013 - 2016: (Nota Técnica Especial). , Fortaleza, CE. Centro de Defesa da Criança e do Adolescente do Estado do Ceará. Recuperado de http://www.cedecaceara.org.br/wp-content/uploads/2013/12/ relatorio_CEDECA_2013-2016.pdf

Butler, J. (2015). Quadros de guerra: Quando a vida é passível de luto. Rio de Janeiro, RJ: Civilização Brasileira.

Carielo, G., \& Grillo, M. (2017, Dezembro 17). Especialistas em segurança pública afirmam que país deve priorizar combate à violência. O Globo. Recuperado de https://oglobo.globo.com/brasil/especialistas-em-seguranca-publica-afirmam-que-pais-deve-priorizar-combate-violencia-22202383

Cavalvante, R. M. B. (2011). Vidas breves: Investigação acerca do assassinato de jovens em Fortaleza (dissertação de mestrado). Programa de Pós-graduação em Políticas Públicas e Sociedade, Universidade Estadual do Ceará, Fortaleza, CE, Brasil.

Cerqueira, D., Lima, R. S., Bueno, S., Neme, C., Ferreira, H., Coelho, D. et al. (2018). Atlas da violência 2018. Rio de Janeiro, RJ: IPEA.

Coimbra, C. (2001). Operação Rio: O mito das classes perigosas. Rio de Janeiro, RJ: Intertexto.

Coimbra, C., \& Nascimento, M. L. (2003). A produção de crianças e jovens perigosos: A quem interessa. In: P. C. P. Fraga, \& J. A. S. Lulianelli (Orgs.), Jovens em tempo real (pp. 58-63). Rio de Janeiro, RJ: DP \& A.

Comitê Cearense pela Prevenção de Homicídios na Adolescência - CCPHA. (2018). Cada vida importa: Relatório do primeiro semestre de 2017. Fortaleza, CE: o autor. Recuperado de https://www.al.ce.gov.br/phocadownload/ relatorio_primeiro_semestre.pdf

Cruz, A. V. H., Minchoni, T., Matsumoto, A. E. \& Andrade, S. S. (2017). A ditadura que se perpetua: Direitos humanos e a militarização da questão social. Psicologia: Ciência e Profissão, 37(no. spe.), 239-252. https://doi. org/10.1590/1982-3703180002017

Diógenes, G. M. S. (1999). Cartografias da cultura e da violência: gangues, galeras e o movimento hip hop (tese de doutorado). Programa de Pós-graduação em Sociologia, Centro de Humanidades, Universidade Federal do Ceará, Fortaleza, Ceará, Brasil.

Fanon, F. (2010). Os condenados da Terra. Juiz de Fora, MG: Editora UFJF.

Fórum Brasileiro de Segurança Pública. (2017). 11º Anuário Brasileiro deSegurança Pública. São Paulo, SP: o autor.

Foucault, M. (2005). Em defesa da sociedade. São Paulo, SP: Martins Fontes.

G1 CE. (2018, Julho 17). Sete chacinas no Ceará deixaram 48 mortos em 2018: Relembre casos. Recuperado de https://gl.globo.com/ce/ceara/noticia/ceara-tem-48-mortes-em-sete-chacinas-em-2018.ghtml

Hilário, L. C. (2016). Da necropolítica à biopolítica: Variações foucaultiana na periferia do capitalismo. Sapere aude, 7, 194-210. Recuperado de http://periodicos.pucminas.br/index.php/SapereAude/article/view/P.21776342.2016v7n13p194/9735

Manso, B. P., \& Dias, C. N. (2017). PCC, sistema prisional e gestão do novo mundo do crime no Brasil. Revista Brasileira de Segurança Pública, 11(2), 10-29. 
Mbembe, A. (2016). Necropolitica. Arte e Ensaios, (32), 123-151.

Mbembe, A. (2017). Políticas da inimizade. Lisboa: Antigona.

Moraes, M. (2010). PesquisarCOM: Política ontológica e deficiência visual. In: M. Moraes, \& V. Kastrup (Orgs.), Exercícios de ver e não ver: Arte e pesquisa com pessoas com deficiência visual (pp. 26-48). Rio de Janeiro, RJ: Nau.

Melo, E. C. (2018, Janeiro 25). Mortes por intervenção policial triplicam no Ceará. Diário do Nordeste. Recuperado de http://diariodonordeste.verdesmares.com.br/cadernos/policia/mortes-por-intervencao-policial-triplicam-no-ceara-1.1884679

Nascimento, A. (2017). O genocídio do negro brasileiro: Processos de um racismo mascarado (2a ed.). São Paulo, SP: Perspectiva.

Paiva, L. F. S. (2018). Dinâmicas das violências em tempos de facções criminosas no Ceará: Cada vida importa. Relatório do segundo semestre de 2017 do Comitê Cearense pela Prevenção de Homicídios na Adolescência. Fortaleza, CE: Comitê Cearense pela Prevenção de Homicídios na Adolescência. Recuperado de http://cadavidaimporta.com.br/wp-content/uploads/2018/05/Relato\%CC\%81rio-2017.2-CORRIGIDO.pdf

Passos, E., Kastrup, V., \& Escossia, L. (2009). Pistas do método da cartografia. Porto Alegre, RS: Sulina.

Passos, E., Kastrup, V., \& Tedesco, S. (2014). Pistas do método da cartografia 2: A experiência da pesquisa e o plano comum. Porto Alegre, RS: Sulina.

Prefeitura de Fortaleza. (2018, Abril 25). Vice-prefeito Moroni Torgan apresenta o Programa Municipal de Proteção Urbana em Fórum Nacional de Segurança. Fortaleza, CE: o autor. Recuperado de https://www.fortaleza.ce.gov. $\mathrm{br} /$ noticias/tag/PMPU

Ramos, S., \& Musumeci, L. (2005) Elemento suspeito: Abordagem policial e discriminação na cidade do Rio de Janeiro. Rio de Janeiro, RJ: Civilização Brasileira.

Ribeiro Junior, A. C. (2016). As drogas, os inimigos e a necropolítica. Cadernos do CEAS, (238), 595-610. Recuperado de https://cadernosdoceas.ucsal.br/index.php/cadernosdoceas/article/view/251

Rocha, M. L., \& Aguiar, K. F. (2003). Pesquisa-intervenção e a produção de novas análises. Psicologia Ciência e Profissão, 23(4), 64-73. https:// doi.org/10.1590/S1414-98932003000400010

Sales, M. A. (2007). (In)visibilidade perversa: Adolescentes infratores como metáfora da violência. São Paulo, SP: Cortez.

Tedesco, S. H., Sade, C. \& Caliman, L. V. (2013). A entrevista na pesquisa cartográfica: A experiência do dizer. Fractal: Revista de Psicologia, 25(2), 299-322. https://doi.org/10.1590/S1984-02922013000200006

Victor, M. (2017, Janeiro 29). 'Bandido terá justiça ou cemitério', diz secretário da segurança do Ceará. G1 CE. Recuperado de http://g1.globo.com/ceara/noticia/2017/01/bandido-tera-justica-ou-cemiterio-diz-secretario-da-seguranca-do-ceara.html

Wacquant, L. (2008). As duas faces do gueto. São Paulo, SP: Boitempo.

Wacquant, L. (2011). As prisões da miséria (2a ed.). Rio de Janeiro, RJ: Zahar.

Waiselfisz, J. J. (2016). Mapa da Violência 2016: Homicídios por armas de fogo no Brasil. Brasília, DF: Flacso.

Zaffaroni, E. R. (2007). O inimigo no direito penal. Rio de Janeiro, RJ: Revan.

\section{Luis Fernando de Souza Benicio}

Psicólogo pela UNIFANOR, Fortaleza - CE. Brasil. Mestre em Psicologia pela Universidade Federal do Ceará. Professor visitante da Escola de Saúde Pública do Estado do Ceará (ESP/CE), Fortaleza - CE. Brasil.

E-mail: luisf.benicio@gmail.com

(iD https://orcid.org/0000-0002-0765-2568

\section{João Paulo Pereira Barros}

Professor Adjunto do Departamento de Psicologia da Universidade Federal do Ceará (UFC), Fortaleza - CE. Brasil. Vice-coordenador do Programa de Pós-Graduação em Psicologia da UFC. Doutor em Educação, mestre e graduado em Psicologia pela UFC. Especialista em Saúde Mental pela Universidade Estadual do Ceará (UECE), Fortaleza - CE. Brasil. 
E-mail: joaopaulobarros07@gmail.com

(iD) https:// orcid.org/0000-0001-7680-576X

Jéssica Silva Rodrigues

Psicóloga pela Universidade Federal do Ceará (UFC), Fortaleza - CE. Brasil. Especialista em Saúde Mental pelo programa de Residência Integrada em Saúde da Escola de Saúde Pública do Ceará (RIS-ESP/CE), Fortaleza - CE. Brasil. Mestranda em Psicologia pela UFC.

E-mail: jsrodriguespsi@gmail.com

(iD https://orcid.org/0000-0001-8395-1626

Dagualberto Barboza da Silva

Graduando no curso de Psicologia da Universidade Federal do Ceará (UFC), Fortaleza - CE. Brasil.

E-mail: dalgobarboza92@gmail.com

(iD) https:// orcid.org/0000-0003-3788-1780

Camila dos Santos Leonardo

Graduanda no curso de Psicologia da Universidade Federal do Ceará (UFC), Fortaleza - CE. Brasil.

E-mail: myllaleonardo32@gmail.com

(iD https:// orcid.org/0000-0001-5889-0155

Aldemar Ferreira da Costa

Psicólogo pela Universidade Federal do Ceará (UFC), Fortaleza - CE. Brasil.

E-mail: demarfcost92@gmail.com

iD https:// orcid.org/0000-0003-0281-9944

Endereço para envio de correspondência:

Departamento de Psicologia da Universidade Federal do Ceará. Centro de Humanidades II / Campus Benfica. Avenida da Universidade, 2762, Benfica, CEP 60.020-180 - Fortaleza CE

Recebido 23/08/2018

Aprovado 27/08/2018

Received $08 / 23 / 2018$

Approved 08/27/2018

Recibido 23/08/2018

Aceptado 27/08/2018

Como Citar: Benício, L. F. S., Barros, J. P. P., Rodrigues, J. S., Silva, D. B., Leonardo, C. S., \& A. F. Costa. (2018). Necropolítica e Pesquisa-Intervenção sobre Homicídios de Adolescentes e Jovens em Fortaleza, CE. Psicologia: Ciência e Profissão, 38(n.spe.2), 192-207. https://doi.org/10.1590/1982-3703000212908

How to Cite: Benício, L. F. S., Barros, J. P. P., Rodrigues, J. S., Silva, D. B., Leonardo, C. S., \& A. F. Costa. (2018). Necropolitics and Intervention-Research on Homicides of Adolescents and Young People in Fortaleza, Ceará. Psicologia: Ciência e Profissão, 38(n.spe.2), 192-207. https://doi.org/10.1590/1982-3703000212908

Cómo Citar: Benício, L. F. S., Barros, J. P. P., Rodrigues, J. S., Silva, D. B., Leonardo, C. S., \& A. F. Costa. (2018). Necropolítica e Investigación-Intervención sobre Homicidios de Adolescentes y Jóvenes en Fortaleza, Ceará. Psicologia: Ciência e Profissão, 38(n.spe.2), 192-207. https://doi.org/10.1590/1982-3703000212908 